\title{
The Reverse Logistics Technology and Development Trend of Retired Home Appliances
}

\author{
Xin Zhao", Yonggao Fu, Jiaqi Hu, Ling Wang, and Meiling Deng \\ China National Electric Apparatus Research Institute Co., Ltd., \\ Guangzhou, China \\ \{zhaox, fuyg, wangl\} @cei1958.com, \\ zhx075@126.com
}

\begin{abstract}
This paper has introduced the status of retired home appliances reverse logistics industry in China, elaborated the key technologies which need to be focused on to enhance the development level of reverse logistics industry, including product life cycle information tracing technology, retired product quality detection technology, inventory optimization control technology, to build efficient reverse logistics information system and lead the industry to develop in the direction of informationization and standardization.
\end{abstract}

Keywords: retired appliance, reverse logistics, development trends.

\section{Introduction}

China is the world's biggest home appliance manufacturing country, has a huge number of home appliances ownership. According to data from the National Bureau of Statistics, our country's social ownership of TV sets, refrigerators, air conditioners, washing machines, computers reached 1.5 billion units in 2011. Faster product replacement product life cycle has been reduced each year due to end-of-life, out of substandard products returned loss is growing at a phenomenal rate. Because of the faster product update speed, shorter product life cycle, the loss caused by discarded, obsolete, unqualified products return is growing at an alarming rate each year.On the other hand, as people's environmental awareness is growing, the government began to require manufacturers to be responsible for the whole process of the product life cycle with legislation, especially in the recycling of waste product."Waste electrical and electronic product recycling management regulation" has formally implemented from the year of 2011, this regulation improves the threshold of waste electrical and electronic products industry, makes the responsibilities of production enterprise, sales enterprise, recycling enterprise, handling enterprise clear. The implementation of this regulation has the significance of the milestone type on the development of the recycling of waste electrical and electronic products industry. Reverse logistics

\footnotetext{
* Corresponding author.
} 
is still a new industry in China, but it can reduce costs, improve the economic efficiency of enterprises, enhance their competitive advantage, improve the living environment of mankind, promote sustainable development, these advantages has attracted the attention of enterprises, so the retired home appliances reverse logistics industry has developed rapidly [1] .

\section{The Development Status of Reverse Logistics Technology}

The research for retired home appliances reverse logistics in china focuses on the following aspects: [2] (1)reverse logistics network design research, which mainly studies network structure characteristics and the construction of model of reverse logistics ; (2)inventory control and management research, which discusses how to the process inventory management of recycled products efficiently and economically ; (3) the effective application of forecasting and decision technology in reverse logistics research, which discusses effective treatment of forecasting and decision technology on uncertainty ,complexity and other factors which exist in the reverse logistics; (4) reverse Logistics Information System research, which analyses the structural characteristics of the reverse logistics system, studies the building of reverse logistics information system.

Above research is basically limited to the theoretical level of mathematical modeling. As for how discarded home appliances characterize, identify and trace the full life cycle information, and how to realize the quality inspection and judgment of retired appliances quickly, to supervise the recycling process effectively, to build reverse logistics management information system are still a lack of systematic research.

\subsection{The Classification and Labeling of Product}

Due to the models, specifications of home appliance products circulating on the market are different at present, if just only trace the information of retired home appliances, it is more cumbersome, so the relevant government departments should study and define the encoding rules in the design, using and maintenance and other stages of the life cycle of home appliances, establish a special classification and coding system.

\subsection{Recovery and Inventory}

At present, the waste home appliances recycling channels are still not perfect, which can be divided into three categories: First, the individual small traders purchase from door to door or at street, which is the most common way to recovery; Second, the home appliances flea market or sales, recycling enterprises purchase and recover, including the successful home appliances enterprise's recovery; Third, organs and institutions trade unified, but this is a very small proportion. It should be based on the existing home appliances products (refrigerators, air conditioners, televisions, computers, washing machines) sales logistics platform and multidimensional recycling (contains a variety of recycled sources, such as scrap, return, fund management, etc.) network 
system to analyze the characteristics of reverse logistics in different ways, to determine the basic operation mode and technical requirements of reverse logistics.

Due to the connection and operation of reverse logistics is uncertain, it should build reverse logistics inventory control model which is suitable for home appliance recycling enterprise. First, considering the time and space factors impact on the overall cost of recycling, the analysis of the quantity drive and time drive mechanism in the recycling enterprise inventory management under the environment of uncertainty sources of quantity and quality. Second, as the demand of home appliance is fuzzy in the reverse logistics, it should through the analysis of the distribution processes of key materials, establishing fuzzy environment multicycle inventory control model, proposing inventory control strategy of the manufacturing enterprises under different conditions, to achieve effective coordination of inventory materials in reverse logistics system between the main enterprise. [3]

\subsection{Dismantling}

To improve the enterprises' efficiency of dismantling, it should accord to the national retirement products, key product disassembly information label specification, to develop the monitoring and control system of information collection system and dismantling process, to realize the identification, collection and data analysis of the EX-warehouse and warehouse information of outbound products and inventory products, real-time tracking of enterprise internal operation, to provide technical means for government regulation.

Combining with the status, and under scientific planning, to promote the area construction of facilities for central treatment of waste electric and electronic products, improve the standardization processing capacity, site selection should be coordinated the planning of urban development, environmental protection, land and so on, should straighten out the dismantling households, sorting and dismantling field and other non-standard processing units, enter the centralized treatment plant which is planed and built by government within a definite time, implement unified management. [4]

\subsection{Remanufacturing}

China is home appliance consumption and production power country, electric and electronic products resources consumption of which is larger. Remanufacturing is refers to through the necessary disassembly, such as repair and replacement of parts, to recover the waste products such as the new process, which can effectively realize the recycling of resources, reduce unnecessary waste. Faced with limited resources and waste disposal capacity, remanufacturing as a senior form of product recycling, can effectively achieve the comprehensive target of optimization utilization of resources, environmental protection and economic sustainable development, has attached great importance to by the government and enterprises, become one of the most effective way to realize sustainable development.[5] 


\section{$3 \quad$ Policy and Measure}

China has carried out the law of "Cleaner Production Promotion Law of the People's Republic of China", according to the Decree 551 of the State Council of the People's Republic of China, since January 1, 2011, "The Management Regulations of recycling of waste electrical and electronic products", has also went into effect.

Guangdong Province for example, by the end of 2015, we forecast that the institutional mechanisms of recycling of waste electrical and electronic products in Guangdong Province are basically perfect, the construction of enterprises with centralized treatment of the four areas, such as the Pearl River Delta, Eastern Guangdong, Western Guangdong, Northern Guangdong, etc. The recycling network and unified norms regulatory system which covers urban and rural are basically established. [6]

Guangdong Province has carried out some specific measures as follows:

1. Focus on strengthening the layout guide, and to build a large-scale centralized processing system, and to promote the cleaner production.

Implement national policies related to subsidies, improve the subsidy audit procedures, and transfer on time the subsidy funds, to speed up dismantling company capital return. Implement the preferential policies of corporate income tax of the comprehensive utilization of resources; provide the processing enterprises tax incentives of the operating income in accordance with the regulations.

Promote the use of recycling technology recommended by "China Resources Comprehensive Utilization Technology Policy", encourage the waste electrical and electronic products processing enterprises to adopt advanced technology and equipment, and conduct the upgrading of technological improvements and dismantling production line. Pursue the cleaner production audits; increase the resource recycling efficiency and the level of environmental pollution prevention and treatment, to build a cleaner production and park. Construct the renewable resources comprehensive utilization information Center, Technology Center, and Key Laboratory in each province, actively organize the development and application of the dismantling of waste electrical and electronic products and the new processes, new technology, new equipment of Pollution prevention.

2. Depending on the construction of network, to build industrialized recycling system and to encourage resource utilization.

Establish a network which covers the communication and exchange of province-wide waste electrical and electronic product recycling information, for the convenience of strengthening the exchange and feedback of information between enterprises. Authorities, organizations and enterprises should inform specific recycling enterprises of fixed asset retirement details, ensuring that electrical and electronic products can be delivered uniformly to qualified enterprises for its recycling and dismantling.

Support Waste electric and electronic products processing enterprises to establish cooperation with manufacturing enterprises, importers, distributors and recycling enterprises, in an endeavor to jointly build a recycling industry chain between the upstream and downstream industries on the manufacturing, recycling, processing, and 
utilization of electrical and electronic products. Through the ordered links of the industry chain and the construction of renewable resources utilization system, improve the rate and levels of resource recovery.

3. By means of strengthening the supervision and management, improve and standardize the unified regulatory system, to ensure the harmlessness.

Strengthen and standardize the management of channels of recycling and circulation of waste electrical and electronic products, and gradually establish a unified and standardized, fair and orderly recycling and circulation order, with clear division. Establish the system of evidence record, filing, registration and management for the waste electrical and electronic product recycling, in order to regulate the auditing of amount of recycling and processing and the fund subsidy program.

Strictly supervise the recycling, transportation, storage and dismantling processes of waste electrical and electronic products, standardize the environmental behavior of dismantling and recycling process of waste electrical and electronic products. Crushing and sorting components, parts with toxic and hazardous substances should be conducted in the closed facilities. Waste gas, dust and other pollutants should be collected and purified, to ensure that it reaches the discharge standards.

\section{$4 \quad$ Summary}

The benign development of reverse logistics of waste electrical and electronic product has caused great attention of the national, so individuals, enterprises , and government need to cooperate. Recycling and re-manufacturing not only reduces the cost of home appliances, but also solves the environmental problems caused by the accumulation of dangerous dismantling .It has an extremely important significance for the sustainable development of the economy. [7] In the technical method of reverse logistics applications, RFID and smart inventory have broad prospects, so the environmental and economic value can be increased by enhancing the efforts of application.

\section{References}

1. Gan, W.-H.: Reverse logistics. Peking University Press (2012)

2. Huang, Z.-Q.: The reverse Logistics Management. Zhejiang University Press (2010)

3. Dai, Y., Ma, Z.-J.: The recycling system and management mechanism of waste home appliances (2010)

4. Yam, J.: The research of reverse logistics network site optimization strategy. China Social and Sciences Press (2011)

5. Yu, O.-D.: The production logistics simulation of the home appliances remanufacturing. Logistics Technology (2009)

6. Environmental protection bureau of Guangdong Province compiled. Audit manual of waste electrical and electronic products dismantling situation (2013)

7. The national development and reform commission resource conservation and environmental protection department compiled. Research and Practice on Waste Electrical and Electronic Product Recovery Processing (2012) 